\title{
Relationship Between Exercise and Bone Mineral Density Among Over 5,000 Women Aged 40 Years and Above
}

\author{
Katsumi Kano
}

\begin{abstract}
An epidemiological survey was conducted to clarify the relationship between bone mineral density(BMD) and exercise at 14 health centers in Ibaraki Prefecture, Japan from September 1994 through March 1995. More than 5,000 women participated in this survey. Second metacarpal BMD was measured by CXD(Computed X-ray Densitometry) method. Information about past history of exercise was obtained by questionnaire. $\Sigma$ GS/D<2.3( $\Sigma$ GS/D : a parameter of BMD ) was used to estimate the suspicion of osteoporosis. Data on 5,124 women aged 40 years and above were analyzed. Subjects were categorized into two groups according to the presence $(n=1,687)$ or absence $(n=3,437)$ of past history of regular exercise. $\Sigma G S / D$ values were significantly $(p \leqq 0.05)$ higher in women who have had regular exercise in the past than those of the non-exercise group except those aged over 70 years. Ball game, foot sports and gymnastics were the main exercises. When osteoporosis was suspected based on the measurements of bone mineral density, the odds ratio (exercise present/absent) was 0.27 (95\% confidence limits : $0.08 \sim 0.94), 0.82(0.65 \sim 1.04), 0.78(0.61-0.99)$, and $1.25(0.67 \sim 2.35)$ at 40 $\sim 49,50 \sim 59,60 \sim 69$, and over 70 years, respectively.

The results of the present study suggest the beneficial influence of exercise on bone mineral density and its utility for preventing osteoporosis. J Epidemiol, $1998 ; 8: 28-32$.
\end{abstract}

exercise, bone mineral density, osteoporosis, middle-aged and elderly women

The population of the elderly has been increasing more rapidly in Japan.

Consequently, diseases due to old age have posed serious social problems. One of such diseases is osteoporosis. The disease as well as cerebral apoplexy is the main cause of bed-ridden in elderly persons. Since severe cardiac and pulmonary function impairment and limitation of movement are caused by low back pain, deformity of the spine, and other symptoms of osteoporosis, activity in the elderly is markedly inhibited and as a result, their QOL declines ${ }^{1-4)}$. Since the incidence of osteoporosis is clearly higher in postmenopausal women and bone fractures are also due to this disease, it is important to carry out surveys and studies for preventing osteoporosis in women, especially in the middle-aged and the elderly.

In the present study, the relationship between bone mineral density closely related to this disease and exercise in the past in local inhabitants was investigated.

\section{MATERIALS AND METHODS}

From September 1994 through March 1995, a questionnaire survey by interviewing concerning exercise and plain $\mathrm{X}$-ray of the hand were carried out in women who received screening for osteoporosis at 14 health centers in Ibaraki Prefecture, Japan. Of 5,483 women, 5,124 excluding those aged under 40 years were studied (Table 1). Subjects were categorized into two groups according to the presence (Exercise group) $(n=1,387)$ or absence(Non-exercise group) $(n=3,437)$ of past history of regular exercise.

Bone mineral density ( $\Sigma$ Gray Scale/Diameter (mm Al) : $\Sigma$ GS/D ) was determined by analyzing X-ray films of the hand (right second metacarpal bone) by computed X-ray densitometry (CXD) using Bonalyzer (Teijin Limited). The relationship between bone mineral density and exercise was assessed using this index mainly for each age group. Based on the

Received April 16, 1997 ; accepted August 7, 1997.

Institute of Community Medicine University of Tsukuba 1-1-1 Tennoudai, Tsukuba-shi, Ibaraki-ken, 305, Japan.

Address for correspondence : Katsumi Kano, Institute of Community Medicine, University of Tsukuba, 1-1-1 Tennoudal, Tsukubashi, lbaraki 305, Japan. 
Table 1. Profile of the subjects.

\begin{tabular}{ll}
\hline occupation & \\
\hline (1) Unemployed & $63.1 \%(n=3,237)$ \\
(2) Farmers & $11.5 \%(n=587)$ \\
(3) Company employees & $6.3 \%(n=322)$ \\
(4) Part-time employees & $5.4 \%(n=278)$ \\
(5) Self-employed & $5.1 \%(n=261)$ \\
(6) Public servants & $3.5 \%(n=178)$ \\
(7) Others & $5.1 \%(n=261)$ \\
Total & $100 \%(n=5,124)$ \\
\hline
\end{tabular}

results of preceding studies,,$^{5-7)}$ osteoporosis was suspected when $\Sigma$ GS/D was less than 2.3 .

Definition of exercise is as follows:

Ball game is defined as sports using balls such as volleyball ,basketball , softball , table tennis, and tennis. Foot sports includes conditioning exercise using legs such as walking, running, jogging and brisk walking. Gymnastics comprise conditioning exercise like stretching, radio - stretching, yoga, dumbbell stretching, aerobics dance, and muscle training. Martial art is defined as contact sports between two or more participants such as judo, karate and kendo.

In order to assess the preventive effect of exercise on osteoporosis, the odds ratio and its $95 \%$ confidence limits were calculated.

\section{RESULTS}

As shown in Table 2, bone mineral density was significantly higher in the exercise group than in the non-exercise group except women aged over 70 years .
Bone mineral density closely related to exercise with age (exercise group : $\mathrm{r}=-0.655, \mathrm{p}<0.01$, non - exercise group : $\mathrm{r}=$ $-0.659, p<0.01$ )( Table 3 )

In the present study, osteoporosis was suspected when bone mineral density ( $\Sigma$ GS/D) was $<2.3$. The value $\Sigma$ GS/D $<2.3$ was increasing with age in both exercise and non-excises groups as shown in Figure 1.

Ball game, foot sports and gymnastics were the main exercises (Figure 2). The frequency of exercise was generally once or twice ( one or two days ) per week in all age groups, while not a few women had performed exercise every day (Figure 3).

The odds ratio for the history of exercise was 0.27 (95\% confidence limits : $0.08 \sim 0.94)$ at $40 \sim 49$ years, $0.82(0.65 \sim$ $1.04)$ at $50 \sim 59$ years, $0.78(0.61 \sim 0.99)$ at $60 \sim 69$ years and $1.25(0.67 \sim 2.35)$ at $\leqq 70$ years (Table 4$)$.

\section{DISCUSSION}

As the population of the elderly has expanded, the incidence of osteoporosis and the number of elderly patients suffering from bone fractures due to this disease have increased. As a result, the number of bed-ridden elderly persons has increased and their QOL has been lowered clearly.

Osteoporosis is defined as a systemic skeletal disease characterized by low bone mass and microarchitectural deterioration of bone tissue, with a resulting increase in bone fragility and susceptibility to fracture. There is a close relationship between bone mineral density and osteoporosis ${ }^{8}$.

Various apparatus for determining bone mineral density have been developed. In the present study, bone mineral density was determined on $\mathrm{X}$-ray films of the hand using a relatively simple, but very reliable densitometer, because it had to be determined almost simultaneously in many at all health centers in Ibaraki Prefecture. Historically, evaluation of bone atro-

Table 2. Height, weight and $\Sigma$ GS/D by exercise and age groups.

\begin{tabular}{|c|c|c|c|c|c|c|c|}
\hline Exercise & Subjects & $\begin{array}{c}\sum \text { GS/D } \\
\text { Mean } \pm \text { S.D }\end{array}$ & $\begin{array}{l}\text { Maximum } \\
\text { Value }\end{array}$ & $\begin{array}{l}\text { Minimum } \\
\text { Value }\end{array}$ & Range & $p$ value & \\
\hline \multicolumn{8}{|l|}{$40-49$ years } \\
\hline - Exercise group & 519 & $2.80 \pm 0.21$ & 3.45 & 2.26 & 1.19 & 0.050 & * \\
\hline - Non-exercise group & 766 & $2.78 \pm 0.23$ & 3.62 & 1.91 & 1.71 & $(t=-1.909)$ & \\
\hline \multicolumn{8}{|l|}{$50-59$ years } \\
\hline - Exercise group & 757 & $2.55 \pm 0.28$ & 3.44 & 1.05 & 2.39 & 0.039 & $*$ \\
\hline - Non-exercise group & 1,406 & $2.35 \pm 0.27$ & 3.43 & 1.53 & 1.90 & $(t=-2.687)$ & \\
\hline \multicolumn{8}{|l|}{$60-69$ years } \\
\hline - Exercise group & 336 & $2.31 \pm 0.24$ & 3.05 & 1.37 & 1.68 & 0.037 & $*$ \\
\hline - Non-exercise group & 1,044 & $2.27 \pm 0.26$ & 3.33 & 1.07 & 2.26 & $(t=-2.087)$ & \\
\hline \multicolumn{8}{|l|}{70 years and above } \\
\hline - Exercise group & 75 & $2.13 \pm 0.27$ & 2.93 & 1.52 & 1.41 & 0.706 & \\
\hline - Non-exercise group & 221 & $2.12 \pm 0.24$ & 2.75 & 1.60 & 1.15 & $(t=0.371)$ & \\
\hline
\end{tabular}

* $\mathrm{p}<0.05$ 
Table 3. Correlation and regression of bone mineral density and age by exercise group and non-exercise group

\begin{tabular}{lcc}
\hline \multicolumn{1}{c}{ Exercise } & Regression & Correlation \\
\hline -Exercise group & $\mathrm{Y}=-0.226 \mathrm{X}+3.980$ & $\mathrm{r}=-0.655(\mathrm{n}=1687) \mathrm{p}=0.0001^{*}$ \\
-Non-exercise group & $\mathrm{Y}=-0.226 \mathrm{X}+3.955$ & $\mathrm{r}=-0.659(\mathrm{n}=3437) \mathrm{p}=0.0001^{*}$ \\
\hline
\end{tabular}

Y:bone mineral density ( $\Sigma$ GS/D) X:age(years)

$* \mathrm{p}<0.001$

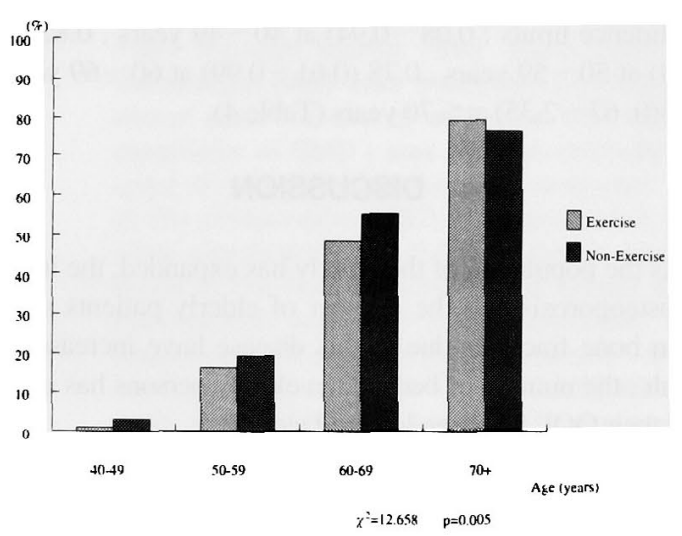

Figure 1. Percent of $\Sigma G S / D<2.3$ by exercise and age.

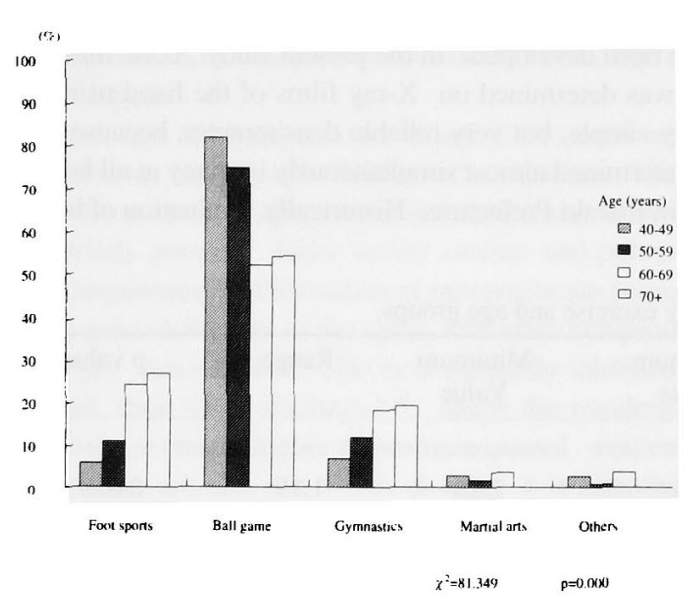

Figure 2. Exercise types.

phy using $\mathrm{X}$-ray films of the hand was done by macroscopic measurement of the width of the metacarpal cortex (metacarpal index ). This method was subsequently used in the world and some reports have been presented concerning its use. In 1980, a new method for determining bone cortical width and bone

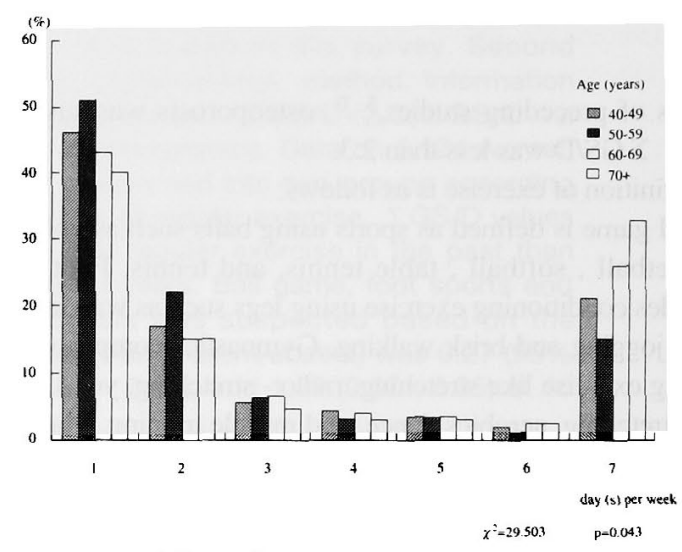

Figure 3.Frequency of exercise.

mineral density as parameters using a computerized densitometer (microdensitometry : MD method) was developed and it has been widely used as a method for determination of metabolic bone diseases.

The new method has the advantages of simple operation and high reproducibility. Moreover, it allows for the measurement of metacarpal bone mineral density and the corresponding bone mineral content that cannot be determined by conventional X-ray densitometry. Measurements obtained by this method are well correlated with those obtained by other methods including dual energy X-ray absorptiometry (DXA) ${ }^{5,7}$. Since only two densitometer units manufactured by the same company were used in the present study, no particular problems were posed as to errors and precision control between testing institutions. Judgments were made at each of the health centers based on the measurements obtained.

In the present study, with reference to the results of preceding studies, osteoporosis was suspected when $\Sigma$ GS/D determined using the densitometer described above was less than $2.3^{9)}$. The incidence of osteoporosis has been reported to be as high as about $50 \%$ and $70 \%$ in women aged over 65 and 80 years, respectively, although there are slight variations between investigational methods. On average, about one-third of elderly persons aged over 65 years may be patients with 
Table 4. Odds ratio and $95 \%$ confidential limit of osteoporosis and history of exercise

\begin{tabular}{lcccc}
\hline \multicolumn{1}{c}{ Exercise } & $\begin{array}{c}\text { Non-osteoporosis } \\
\Sigma \text { GS/D } \geq 2.3\end{array}$ & $\begin{array}{c}\text { osteoporosis } \\
\Sigma \text { GS/D<2.3 }\end{array}$ & Odds ratio 95\%CI \\
\hline $40-49$ years & & & & \\
- Exercise group $(\mathrm{n}=519)$ & $99.4 \%(\mathrm{n}=516)$ & $0.6 \%(\mathrm{n}=3)$ & 0.27 & $0.08-0.94$ \\
- Non-exercise group $(\mathrm{n}=766)$ & $97.9 \%(\mathrm{n}=750)$ & $2.1 \%(\mathrm{n}=16)$ & & \\
50-59 years & & & & \\
- Exercise group $(\mathrm{n}=757)$ & $83.8 \%(\mathrm{n}=634)$ & $16.2 \%(\mathrm{n}=123)$ & 0.82 & $0.65-1.04$ \\
- Non-exercise group $(\mathrm{n}=1,406)$ & $80.9 \%(\mathrm{n}=1,138)$ & $19.1 \%(\mathrm{n}=268)$ & & \\
60-69 years & & & & \\
- Exercise group $(\mathrm{n}=336)$ & $52.1 \%(\mathrm{n}=175)$ & $47.9 \%(\mathrm{n}=161)$ & 0.78 & $0.61-0.99$ \\
- Non-exercise group $(\mathrm{n}=1,044)$ & $45.8 \%(\mathrm{n}=478)$ & $54.2 \%(\mathrm{n}=566)$ & & \\
70 years and above & & & & \\
- Exercise group $(\mathrm{n}=75)$ & $21.3 \%(\mathrm{n}=16)$ & $78.7 \%(\mathrm{n}=59)$ & 1.25 & $0.67-2.35$ \\
- Non-exercise group $(\mathrm{n}=221)$ & $25.3 \%(\mathrm{n}=56)$ & $74.6 \%(\mathrm{n}=165)$ & & \\
\hline
\end{tabular}

osteoporosis ${ }^{10}$ ). Our result was almost the same. The present study was carried out in general inhabitants who hoped to screen for osteoporosis, while patients who were actively receiving treatment for this disease and those hospitalized because of some disease were excluded. However, the incidence of this disease may show little difference between this and other regions. Bone mineral density closely related to osteoporosis was well correlated with age ( exercise group $: r=$ $-0.655, \mathrm{p}<0.01$, non-exercise group : $\mathrm{r}=-0.659, \mathrm{p}<0.01$ ) as had been expected. This result suggests that osteoporosis is an aging disease which is related to old age and that age must be taken into account when this disease or bone mineral density is discussed. In the present study, the significance of differences in bone mineral density between the exercise and nonexercise groups was assessed for each age group so that the influence of age was removed.

In this study there were no significant differences in the history of ovariectomy, thyroid disease , parathyroid disease and so on producing an influence on bone mineral density in woman between the exercise and non-exercise groups. Also no significant differences were noted either in relation to the presence or age of menopause between the two groups. The influence of physical activities on bone mineral density and how it is closely related to osteoporosis have only been studied since the latter half of the $1970 \mathrm{~s}$ when it became possible to determine bone mineral density relatively easily.

However, it is not too much to say that few studies have been carried out concerning osteoporosis in over 5,000 local inhabitants. Since the present study was carried out in such a large number of subjects, the reliability of results may be higher.

It is difficult to define exercise and determine its amount and frequency objectively and quantitatively, while whether or not the subjects have a history of exercise can be determined rela- tively accurately with high reproducibility. Therefore, the subjects of the present study were classified based on the history of exercise in order to assess the influence of exercise on bone mineral density. Since the present study was carried out by the usual remembering method, the possibility cannot be ruled out that there was slight bias due to differences in the power of memory of subjects and in the interviewing ability of interviewers . However, as a great number of women were studied, such a bias, if any, was considered to produce no significant influence on the results of the present study. Only answers with high reliability and probability were subjected to data analysis.

In the present study, aside from women aged over 70 years, measurements of bone mineral density were significantly higher in the exercise group with a history of exercise at regular intervals than in the non-exercise group without a history of exercise, and the beneficial effect of exercise was suggested. In addition, results suggesting the same effect were obtained with the odds ratio. As exercise, ball game, foot sports, and gymnastics were more popular and not a few woman had been performing exercise every day in all age groups.

The influence of exercise on bone metabolism is described as follows. With an increase in muscle mass followed by an increase in blood flow in the bone marrow, the turnover of bone is enhanced and osteoblasts are activated to cause osteogenesis, while bone mass increases in the direction of functional external force to the bone to activate osteoblasts by mechanical deformation pressure via electric stimulation . There are many reports concerning the utility of exercise as a therapy for the prevention of osteoporosis in the middle-aged and elderly persons. Exercise has been reported to be effective even in postmenopausal women. According to Buchanan et $\mathrm{al}^{11)}$. who investigated the effect of postmenopausal exercise therapy, the calcium content of the body was increased by 
about $40 \mathrm{~g}$ (accounting for about $5 \%$ of total bone mineral content ) after one year of exercise, compared with the non-exercise group . On the other hand, Aloria et al ${ }^{12)}$. reported that bone mineral density of the body showed an increase after one year of indoor exercise at regular intervals (one-hour exercise once a week ) in women five years after menopause. According to Dalsky ${ }^{13)}$, bone mineral density showed a significant increase after exercise with a maximum oxygen consumption $\left(\mathrm{VO}_{2} \max \right)$ of $60 \% \sim 70 \%$ in the elderly and returned to the pre-exercise level after discontinuation . Even healthy persons showed a marked decrease in the bone mineral density of the body, lumbar vertebrae, and extremities after 17 weeks of bed rest ${ }^{14)}$. Similarly, bone resorption was promoted and calcification of bone was retarded even after 120 days of bed rest ${ }^{15}$.

These studies are classified as cross sectional and longitudinal based on the method of investigation. In particular, middleaged to elderly women were studied longitudinally. They preferred foot sports, gymnastics, and weight training and continued for months to years ${ }^{15,16}$. In the present study, as described above, bone mineral density was significantly higher in the exercise group than in the non-exercise group. It has been clarified that without exercise, calcium is excreted into urine via the kidneys without binding to the bone even when it has been ingested in large quantities from food and active vitamin D has been increased by sunbathing. On the other hand, with exercise, blood flow in the bone is increased and osteogenic cells are activated, resulting in easy binding of calcium ion to the bone.

With an increase in the population of the elderly, patients with chronic diseases due to old age have also increased in number, resulting in an increase of medical expenses.

Considering the natural history of osteoporosis, this disease may be significantly influenced by age. It is impossible to control age, but living habits can be improved. It has been indicated that exercise as one of living habits is effective for curculatory and glucose metabolism diseases when used as prophylactic or non-drug therapy (lifestyle modification therapy). As described above, the possibility is suggested that osteoporosis that is closely related to bone mineral density can also be prevented by habitual exercise.

\section{ACKNOWLEDGMENTS}

I would like to thank each health center and Adult Disease Prevention Section, Ibaraki Prefecture for their cooperation.

\section{REFERENCES}

1. Cook DJ, Guyatt GH, Adachi JD, et al. Quality of life issues in women with vertebral fractures due to osteoporosis. Arthritis and Rheumatism 1993;36:750-756.
2. Greemdale GA, Silverman SL, Hays RD, et al. Healthrelated quality of life in osteoporosis clinical traials., Cacified Tissue International 1993;53:75-77.

3. Kanis JA, Minne WH, Meunier PJ, et al. Quality of life and vertebral osteoporosis, Osteoporosis International 1992;26:161-163.

4. Ruegsgger $P$, Dambacher MA, Ruegsegger E, et al. Bone loss in premenopausal and postmenopausal women. J Bone Joint Surg 1984;66:1015-1023.

5. Matsumoto C. Practical aspects of various methods for determining bone mineral density-Modified MD method (CXD method ) .THE BONE, 1991; 5(3):53-58(in Japanese).

6. Matsumoto $\mathrm{C}$. A newly developed $\mathrm{X}$ - ray bone mineral densitometer for the hand and its basic performance. IGAKUNO AYUMI 1991;156:741-742(in Japanese).

7. Matsumoto C. Bone mineral density of the second metacarpal bone determined by microdensitometry (modified MD method),SEIKEI GEKA, $1992 ; 43: 1140$ 1146(in Japanese).

8. Concensus development conference. Diagnosis, prophylaxis, and treatment of osteoporosis 1993;94:646-650.

9. Elderly health division, Japanese ministry of health and welfare, A manual for the screening test of osteoporosis based on the elderly health laws, Nihon-iji shinposha , 1995(in Japanese).

10. Elderly health division, Japanese ministry of health and welfare. A manual for the prevention of osteoporosis due bed-ridden, Osteoporosis foundation, 1993(in Japanese).

11. Buchanan JR, Myers C, Lloyd T, et al. Determinants of peak trabecular bone density in women : the role of androgens estrogen and exercise. J Bone Miner Res 1988;3:673-680.

12. Aloia JF, Cohn SH, Ostuni JA, et al. Prevention of involutional bone loss. Ann Int Med 1978;89:356-358.

13. Dalsky GP, Stocke KS, Ehsani AA, et al.Weigt-bearing exercise training and lumber bone mineral content in postmenopausal women. Ann Int Med 1988;108:824828.

14. Leblanc AD, Schneider VS, Evans HJ, et al. Bone mineral loss and recovery after 17 weeks bed rest. $\mathrm{J}$ of Bone Mineral Res 1990;5:843-850.

15. Vico L, Chappard D, Alexandre C. et al. Effects of a 120 day period of bed-rest on bone mass and bone cell activities in man - Attempts at countermeasure. Bone and Mineral 1987;2:383-39.

16. Snow-Harter, C. \& Marcus, R, 1991. Exercise, bone mineral and osteoporosis, Exercise and Sports Sciences Reviews, 1991;19:351-388.

17. Riggs BL. Overview of osteoporosis, West J Med 1992;154:63-77. 